\title{
At the Forefront of Nuclear Materials Science with Assel Aitkaliyeva
}

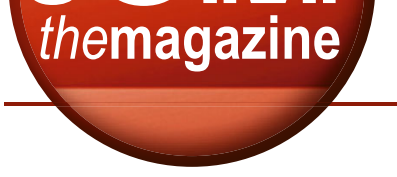

\section{young professional technical notes}

This occasional feature highlights the scientific interests and professional accomplishments of a young TMS member who has contributed to the technical content of the current issue of JOM as an author, advisor, or guest editor.

The development of this feature is a special project of the TMS Young Professionals Committee. For additional information contact Kaitlin Calva, JOM Magazine Managing Editor, at kcalva@tms.org.

\section{Kaitlin Calva}

"The beauty of nuclear materials science is that the challenges are numerous, but you get to stay at the forefront of science," said Assel Aitkaliyeva, assistant professor in the Department of Materials Science and Engineering at the University of Florida (UF), and co-author of the January 2020 JOM paper, "Towards Bridging the Experimental Length-Scale Gap for Tensile Tests on Structural Materials: Lessons Learned from an Initial Assessment of Micro-tensile Tests and Path Forward." "And I get to destroy materials for a living in a creative way!" she added.

Aitkaliyeva began her undergraduate studies at Kazakh State University in nuclear physics, switching to nuclear engineering for her M.S. and Ph.D. at Texas A\&M University. "While working on my master's degree, I discovered that I was passionate about the materials science aspect of the nuclear industry. My earlier exposure to physics and engineering provided me with a unique perspective and I wanted to know how any given material does in a harsh environment."

After earning her Ph.D. and working in postdoctoral and staff positions at Idaho National Laboratory, she joined UF and formed the MAterials for Nuclear Advancement and Technology in Extreme Environments (MANATEE) group. "Our

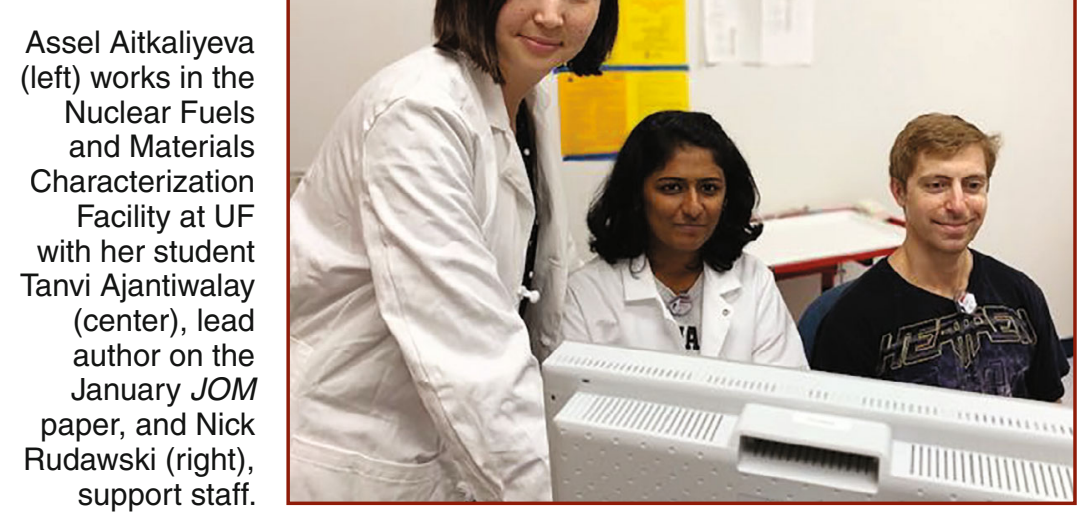

primary research pillars are nuclear fuels, irradiation damage in structural materials and waste storage media, and defect engineering in low-dimensional materials," she said. "The JOM paper highlights just one part of our research-small-scale mechanical testing and its implementation in the nuclear field. Out of the small-scale mechanical tests, micro-tensile tests are the easiest to analyze, data-wise, and we evaluate the suitability of this approach for testing nuclear materials. This is the first step of our journey, and we are excited to expand the technique to nuclear fuels."

When reflecting back on her career and education, Aitkaliyeva expressed her gratitude for the many mentors who piqued her interest in science. "My M.S. and Ph.D. advisor Lin Shao encouraged me to strive for excellence," she said, noting that it was Shao's support of her choosing her own projects that led her to her work today. Instead of continuing with work that did not interest her, Aitkaliyeva saw an opportunity to move to something more compellingtesting the stability of one-dimensional materials. "Carbon nanotubes fascinated me then," she said. "My interest in carbonbased materials was sparked by Mildred Dresselhaus, the 'queen of carbon science.' I got to meet her at several conferences, and she was (and still is, despite her passing) an example for me."

Beyond her mentors, Aitkaliyeva also recognized the impact that being a TMS member has had on her career. "It provided me with networking opportunities while expanding my knowledge base. Since TMS spans a wide range of topics, it never fails to educate you on all aspects of materials science and allows you to look at any problem from multiple points of view," she said. To young scientists and engineers just starting out in the field, Aitkaliyeva advised: "Don't be afraid to step outside of your comfort zone! Get engaged with a professional society and network. Your research will benefit from it." 